\title{
Efeito da Adubação e do Uso de Nematicida na Composição Química da Palma Forrageira (Opuntia ficus indica Mill) ${ }^{1}$
}

\author{
Margareth Maria Teles ${ }^{2}$, Mércia Virgínia Ferreira dos Santos ${ }^{3}$, José Carlos Batista Dubeux \\ Junior ${ }^{3}$, Mário de Andrade Lira ${ }^{3}$, Rinaldo Luiz Caraciolo Ferreira ${ }^{3}$, Egídio Bezerra Neto ${ }^{4}$, \\ Iderval Farias ${ }^{5}$
}

\begin{abstract}
RESUMO - O experimento foi realizado em casa de vegetação do Departamento de Zootecnia da UFRPE, com o objetivo de avaliar o efeito da adubação e de nematicida na composição da palma forrageira cv. gigante, com sintoma de amarelecimento. Para o plantio utilizaram-se cladódios de cor amarela de palma (Opuntia ficus indica, Mill. Cv. Gigante) provenientes da Estação Experimental de Caruaru - IPA, onde foi observado o amarelecimento das plantas. Os tratamentos constaram da presença e ausência de macronutrientes, micronutrientes e de nematicida, em delineamento experimental de blocos ao acaso, com quatro repetições. Não foram observadas diferenças significativas entre os tratamentos para teores de matéria seca, de K, de Ca e de Mg. Para teores de N, de P e de S, a análise de variância revelou diferença significativa. A média geral para teores de MS, N, P, K, Ca, Mg e S foi de 7,29; 1,19; 0,17; 3,31; 1,84; 0,59 e $0,17 \%$, respectivamente. A adição de micronutrientes e de nematicida não influenciou os resultados obtidos para teores de $N$, P, K, Ca, Mg e S. Os teores de nitrogênio, fósforo e potássio foram superiores nos cladódios mais jovens da planta. Os nutrientes nitrogênio, fósforo e enxofre foram os únicos que influenciaram a composição química.
\end{abstract}

Palavra-chave: amarelecimento, cactácea, micronutrientes

\section{Fertilization and Nematicide Effects on the Chemical Composition of Cactus Forage cv. "Gigante"}

\begin{abstract}
This experiment was carried out in a greenhouse at the Animal Science Department/UFRPE and aimed to evaluate the fertilization and nematicide effects on the chemical composition of cactus forage cv. "Gigante" suffering chlorotic symptoms. Chlorotic cladodes of Cactus forage cv. "Gigante" were used as planting material and they were collected at the Caruaru Experimental Station/IPA in the same location where those symptoms were previously observed. The treatments tested the presence or absence of macronutrients, micronutrients, and nematicide. A completely randomized block design was used and the treatments were replicated four times. No significant differences were found for dry matter, K, Ca, and Mg concentration. Significant differences were observed for $\mathrm{N}, \mathrm{P}$, and S concentrations. The mean values for DM, N, P, K, Ca, Mg, and S were 7.29, 1.19, 0.17, 3.31, 1.84, 0.59, and 0.17\%, respectively. Micronutrients and nematicide addition did not alter the N, P, K, Ca, Mg, and S concentrations. Younger cladodes presented higher concentration of N, P, and K. Chemical composition was affected only by $\mathrm{N}, \mathrm{P}$, and $\mathrm{S}$.
\end{abstract}

Palavra-chave: cactaceae, yellowness, micronutrients

\section{Introdução}

A palma forrageira é uma cultura bem adaptada às condições adversas do semi-árido. É uma forrageira que contém, em média, 90\% de água, que contribui para aliviar a sede dos rebanhos, principalmente na época seca (Viana, 1969), além de ser altamente produtiva, rica em mucilagem e minerais (Costa et al., 1973).

A composição química da palma forrageira varia segundo a espécie, cultivar e idade do cladódio (San- tos et al., 1990). A palma forrageira é considerada um material de valor nutritivo elevado e persistente, de alta digestibilidade (Farias et al., 1989; Santos et al., 1998) e elevado teor de minerais (Santos et al., 1997).

O espaçamento no plantio da palma forrageira varia de acordo com a fertilidade do solo, quantidade de chuvas, finalidade de exploração e com sua utilização ou não em consórcio com outras culturas. O cultivo da palma forrageira em espaçamento adensado tem sido mais utilizado, pois, nesses espaçamentos, há maior extração de nutrientes do

\footnotetext{
${ }^{1}$ Parte da Dissertação apresentada ao Programa de Pós-Graduação em Zootecnia-UFRPE; Trabalho realizado pelo Acordo IPA-UFRPE.

${ }^{2}$ Aluno do Programa de Doutorado Integrado em Zootecnia-UFC (margarethmariateles@yahoo.com.br).

3 Professor da UFRPE, bolsista CNPq (mercia@ufrpe.br; mlira@ipa.br; dubeux@edu.ufl; rinaldof@ufrpe.br).

${ }^{4}$ Professor da UFRPE (egidio@ufrpe.br).

${ }^{5}$ Pesquisador do IPA (iderval@ipa.br).
} 
solo, exigindo maior cuidado com a adubação em áreas cultivadas com essa cultura. Com espaçamento adensado, tem-se observado a ocorrência de amarelecimento dos palmais nos Estados de Pernambuco e Alagoas. Supõe-se que tal amarelecimento, com base em observação in loco, seja decorrente da deficiência de algum nutriente no solo ou do aparecimento de nematóides que podem inibir a absorção de nutriente pela cultura (Teles et al., 2002). Análises preliminares indicaram a presença de nematóides na palma originada da área onde foram constatados os sintomas de amarelecimento, justificando a inclusão do nematicida como tratamento. Por outro lado, análises do tecido vegetal do cladódio também evidenciaram menores teores de $\mathrm{N}$ e Mg na palma com sintomas de amarelecimento, quando comparada à palma sem este sintoma. Logo, a deficiência de nutrientes também passou a ser considerada uma das possíveis causas do amarelecimento do palmal.

Objetivou-se, com este trabalho, determinar o efeito da adubação e do uso de nematicida na composição química da palma forrageira coletada em área que apresentava o sintoma de amarelecimento.

\section{Material e Métodos}

O experimento foi conduzido em telado do Departamento de Zootecnia da Universidade Federal Rural de Pernambuco, no período de junho de 1998 a março de 1999. O solo avaliado era proveniente da Estação Experimental de Caruaru - IPA, coletado próximo ao local onde foi observado o amarelecimento da palma forrageira. A análise de fertilidade do solo foi realizada segundo metodologia da EMBRAPA (1979) e revelou os seguintes resultados: $\mathrm{Na}^{+}=0,09 \mathrm{cmol}_{\mathrm{C}} \cdot \mathrm{kg}^{-1} ; \mathrm{K}^{+}=0,32 \mathrm{cmol}_{\mathrm{C}} \cdot \mathrm{kg}^{-1}$; $\mathrm{Ca}^{2+}=1,90 \mathrm{cmol}_{\mathrm{c}} \cdot \mathrm{kg}^{-1} ; \mathrm{Mg}^{2+}=0,90 \mathrm{cmol}_{\mathrm{C}} \cdot \mathrm{kg}^{-1}$; $\mathrm{H}^{+}=1,99 \mathrm{cmol}_{\mathrm{C}} \cdot \mathrm{kg}^{-1} ; \mathrm{Al}^{3+}=0,05 \mathrm{cmol}_{\mathrm{C}} \cdot \mathrm{kg}^{-1}$; $\mathrm{pH}=5,5 ; \mathrm{P}=8,63 \mathrm{mg} \cdot \mathrm{kg}^{-1} ; \mathrm{N}=0,6$ g. $\mathrm{kg}^{-1} ; \mathrm{M} . \mathrm{O} .=$ 7,6 g. $\mathrm{kg}^{-1}$. Vale ressaltar que o baixo nível de matéria orgânica apresentado pode ser uma das possíveis causas do amarelecimento do palmal.

Empregaram-se vasos plásticos medindo $30 \mathrm{~cm}$ de diâmetro por $22 \mathrm{~cm}$ de altura, nos quais foram colocados drenos de aproximadamente $10 \mathrm{~cm}$ de comprimento e diâmetro de 1/4" e camada de brita para evitar o entupimento. A brita foi lavada em água corrente e depois fervida. Foram colocados $15 \mathrm{~kg}$ de solo em cada vaso.

R. Bras. Zootec., v.33, n.6, p.1992-1998, 2004 (Supl. 2)
Para o plantio utilizaram-se cladódios de cor amarela de palma (Opuntia ficus indica, Mill. Cv. Gigante) provenientes também da Estação Experimental de Caruaru - IPA, onde foi observado o amarelecimento das plantas. Os cladódios foram deixados à sombra durante cinco dias e plantados (um cladódio por vaso) verticalmente, com a parte cortada voltada para o solo a uma profundidade de aproximadamente $20 \mathrm{~cm}$. Foi aplicada água destilada duas vezes por semana até a drenagem, sendo a solução drenada, recolhida em um recipiente e retornada ao vaso.

Os tratamentos experimentais constaram da adição ou não de macronutrientes, micronutrientes e de um nematicida sistêmico, perfazendo 17 tratamentos, conforme descritos a seguir: testemunha, testemunha mais nematicida, testemunha mais nitrogênio, testemunha mais fósforo, testemunha mais potássio, testemunha mais cálcio, testemunha mais magnésio, testemunha mais enxofre, solução de macronutrientes completa SMC (N, P, K, Ca, Mg, S), SMC menos nitrogênio, SMC menos fósforo, SMC menos potássio, SMC menos cálcio, SMC menos magnésio, SMC menos enxofre, SMC mais micronutrientes, SMC mais micronutrientes mais nematicida. Foi adotado delineamento de blocos ao acaso com quatro repetições por tratamento. O peso inicial dos cladódios foi utilizado como critério para formação dos blocos, de modo que a variação de peso dentro de cada bloco foi minimizada.

Os cálculos para quantidade de cada nutriente para os vasos foram feitos de acordo com a quantidade de solo colocada em cada vaso $(15 \mathrm{~kg})$, densidade aparente do solo $\left(1,4 \mathrm{t} / \mathrm{m}^{3}\right)$ e profundidade efetiva das raízes $(20 \mathrm{~cm})$.

A aplicação dos tratamentos experimentais foi realizada 52 dias após o plantio, quando $80 \%$ dos vasos apresentavam o aparecimento de pelo menos um novo cladódio. Foram utilizados os níveis equivalentes de adubação: $\mathrm{N}$ - $200 \mathrm{~kg} / \mathrm{ha} ; \mathrm{P}_{2} \mathrm{O}_{5}$ 100 kg/ha; $\mathrm{K}_{2} \mathrm{O}$ - $200 \mathrm{~kg} / \mathrm{ha}$; Ca - $250 \mathrm{~kg} / \mathrm{ha} ; \mathrm{Mg}$ $80 \mathrm{~kg} / \mathrm{ha}$ e S - $20 \mathrm{~kg} / \mathrm{ha}$. Os níveis de adubação utilizados basearam-se nos teores médios de nutrientes minerais encontrados em plantas de palma e nos resultados médios da análise do solo de Caruaru - PE, sendo os adubos aplicados na superfície do solo. As fontes de nutrientes utilizadas, conforme os tratamentos experimentais, foram: uréia, superfosfato triplo, cloreto de potássio, óxido de cálcio, cloreto de 
magnésio, sulfato de magnésio, fosfato de sódio, sulfato de amônio, sulfato de sódio e, para os micronutrientes, foi utilizado o coquetel de micronutrientes e Fe - EDTA da solução de Hoagland \& Arnon (1950).

A adubação nitrogenada foi parcelada em duas vezes, sendo a primeira adubação aplicada juntamente com os outros tratamentos, ou seja, a partir do aparecimento de pelo menos um cladódio. A segunda parcela foi aplicada 45 dias após a primeira adubação.

Conforme os tratamentos experimentais, foram aplicados $5 \mathrm{~g} /$ vaso do nematicida sistêmico Carbofuran (Furadan, $50 \mathrm{~g}$ ) na parte superficial do solo do vaso.

A colheita foi realizada após nove meses de cultivo. A parte aérea foi colhida por planta e por ordem de aparecimento dos cladódios, pesada, fragmentada e acondicionada em sacos de papel devidamente identificados, sendo em seguida colocada em estufa de aeração forçada a $55^{\circ} \mathrm{C}$ até peso constante. Após a pré-secagem, procedeu-se ao processamento em moinho de facas com peneiras de $1 \mathrm{~mm}$ e, em seguida, ao acondicionamento em sacos plásticos identificados para as análises subseqüentes.

O teor de matéria seca foi determinado segundo metodologia descrita por Silva \& Queiroz (2002) no Laboratório de Nutrição Animal do Departamento de Zootecnia da UFRPE.

Para determinação de nitrogênio $(\mathrm{N})$, proteína bruta (PB), fósforo $(\mathrm{P})$, potássio $(\mathrm{K})$, cálcio $(\mathrm{Ca})$ e magnésio (Mg), foi adotada a metodologia descrita por Bezerra Neto et al. (1994). A determinação de enxofre (S) foi obtida pelo método turbidimétrico do sulfato de bário, medida em espectofotômetro de acordo com Malavolta (1997). Os teores de minerais foram determinados no Laboratório de Química Vegetal do Departamento de Química da UFRPE.

A análise dos dados foi realizada por meio do programa computacional SAEG (Sistema para Análises Estatísticas e Genéticas), desenvolvido pela Universidade Federal de Viçosa.

As médias dos tratamentos foram submetidas ao teste de Scott-Knott (Scott \& Knott, 1974), a 5\% de probabilidade.

\section{Resultados e Discussão}

A análise de variância não revelou diferenças significativas $(\mathrm{P}>0,05)$ entre os tratamentos com relação à variável matéria seca. O teor médio de matéria seca foi de 7,29\%, tendo como limites mínimo e máximo os valores de 6,00 e 8,88\%, respectivamente. Estes valores são considerados baixos, quando comparados aos relatados por Santos et al. (1997) e Wanderley (2001), para a mesma espécie e cultivar, em que obtiveram 10,20 e 12,63\%, respectivamente. Ressalta-se que, no presente experimento, foram realizadas irrigações semanais, contribuindo para o mais baixo teor de MS reportado para palma forrageira na literatura. Além disso, os menores valores de matéria seca observados neste trabalho, em relação aos reportados na literatura, podem também estar associados à idade das plantas avaliadas - no caso foi de nove meses de idade, em contraste com a colheita normalmente realizada aos 24 meses - e à presença de artículos novos e em expansão. Os baixos valores de matéria seca da palma podem estar associados ao crescimento lento apresentado pelas plantas CAM (ou MAC - metabolismo ácido das crassuláceas), quando comparado ao das plantas $\mathrm{C}_{3}$ e $\mathrm{C}_{4}$ (Larcher, 1986), mantendo seu valor nutritivo por mais tempo.

Os resultados obtidos para teores de nitrogênio, fósforo, potássio, cálcio, magnésio e enxofre da palma forrageira, são apresentados na Tabela 1. Pela análise de variância, não foram detectadas diferenças significativas $(\mathrm{P}>0,05)$ entre os tratamentos para os teores de potássio, cálcio e magnésio da palma forrageira. Estes resultados podem estar relacionados à fertilidade do solo, cuja análise revelou a presença de elevados níveis de potássio e médios de cálcio e de magnésio, conforme classificação de Malavolta (1979).

O nematicida não promoveu diferença significativa para o tratamento testemunha para qualquer característica analisada. Vale ressaltar que, no decorrer do experimento, não foi observado aparecimento da coloração amarela nos cladódios da planta, permanecendo essa característica apenas no material de plantio (cladódio mãe).

Para nitrogênio, a análise de variância comprovou efeito significativo entre os tratamentos $(\mathrm{P}<0,05)$ pelo teste F. Considerando apenas o grupo dos tratamentos-testemunha, observou-se que a adição de nitrogênio e enxofre aumentou significativamente a porcentagem de nitrogênio (1,46 e 1,19\%, respectivamente), o que pode estar associado à ligação direta do nitrogênio e do enxofre para formação da proteína. Os valores de nitrogênio variaram de $0,79 \%$ a $1,52 \%$, para os tratamentos solução de macronutrientes completa (SMC) - N e SMC - Ca, respectivamente. Além disso, considerando o grupo 
Tabela 1 - Teores de nitrogênio $(\mathrm{N})$, fósforo $(\mathrm{P})$, potássio $(\mathrm{K})$, cálcio $(\mathrm{Ca})$, magnésio $(\mathrm{Mg})$ e enxofre $(\mathrm{S})$ da palma forrageira $\mathrm{CV}$. gigante aos nove meses de idade

Table 1 - Nitrogen $(N)$, phosphorus $(P)$, potassium $(K)$, calcium (Ca), magnesium $(\mathrm{Mg})$ and sulphur $(\mathrm{S})$ concentrations of the cactus forage cv "Gigante" at nine months of regrowth; average data

\begin{tabular}{|c|c|c|c|c|c|c|}
\hline $\begin{array}{l}\text { Tratamentos } \\
\text { Treatments }\end{array}$ & $\mathrm{N}$ & $\mathrm{P}$ & $\mathrm{K} *$ & $\mathrm{Ca} *$ & $\mathrm{Mg} *$ & $\mathrm{~S}$ \\
\hline & & & $\%$ & & & \\
\hline Testemunha (Control) & $1,14 b$ & $0,14 b$ & 2,78 & 2,10 & 0,60 & $0,20 \mathrm{a}$ \\
\hline Test. + nematicida (Control + nematicide) & $1,04 \mathrm{~b}$ & $0,12 b$ & 3,11 & 2,69 & 0,65 & $0,18 \mathrm{a}$ \\
\hline Testemunha $+\mathrm{N}($ Control $+N)$ & $1,46 \mathrm{a}$ & $0,11 b$ & 3,01 & 1,77 & 0,43 & $0,14 b$ \\
\hline Testemunha $+\mathrm{P}($ Control $+P)$ & $1,02 b$ & $0,23 \mathrm{a}$ & 3,34 & 1,96 & 0,59 & $0,20 \mathrm{a}$ \\
\hline Testemunha $+\mathrm{K}($ Control $+K)$ & $0,95 b$ & $0,09 \mathrm{~b}$ & 4,27 & 1,89 & 0,66 & $0,15 b$ \\
\hline Testemunha + Ca (Control $+\mathrm{Ca})$ & $0,94 b$ & $0,08 \mathrm{~b}$ & 3,35 & 1,74 & 0,50 & $0,14 b$ \\
\hline Testemunha $+\mathrm{Mg}($ Control $+\mathrm{Mg})$ & $0,94 b$ & $0,12 b$ & 3,31 & 1,65 & 0,56 & $0,15 b$ \\
\hline Testemunha + S (Control + S) & $1,19 \mathrm{a}$ & $0,10 \mathrm{~b}$ & 3,48 & 1,97 & 0,54 & $0,16 b$ \\
\hline Solução macronutrientes completa (SMC) & $1,24 \mathrm{a}$ & $0,18 \mathrm{a}$ & 2,83 & 1,65 & 0,57 & $0,15 b$ \\
\hline \multicolumn{7}{|l|}{ Complete macronutrient solution (CMS) } \\
\hline $\mathrm{SMC}-\mathrm{NC}(M S-N)$ & $0,79 \mathrm{~b}$ & $0,23 \mathrm{a}$ & 3,29 & 1,80 & 0,56 & $0,22 \mathrm{a}$ \\
\hline $\mathrm{SMC}-\mathrm{PC}(M S-P)$ & $1,18 \mathrm{a}$ & $0,10 \mathrm{~b}$ & 3,42 & 1,62 & 0,53 & $0,15 b$ \\
\hline $\mathrm{SMC}-\mathrm{KC}(M S-K)$ & $1,40 \mathrm{a}$ & $0,24 \mathrm{a}$ & 2,33 & 1,95 & 0,65 & $0,19 \mathrm{a}$ \\
\hline $\mathrm{SMC}-\mathrm{Ca}(C M S-C a)$ & $1,52 \mathrm{a}$ & $0,30 \mathrm{a}$ & 3,56 & 1,58 & 0,70 & $0,18 \mathrm{a}$ \\
\hline $\mathrm{SMC}-\mathrm{Mg}(C M S-M g)$ & $1,41 \mathrm{a}$ & $0,23 \mathrm{a}$ & 3,79 & 1,60 & 0,55 & $0,19 a$ \\
\hline$S M C-S(C M S-S)$ & $1,37 \mathrm{a}$ & $0,22 \mathrm{a}$ & 3,46 & 1,70 & 0,49 & $0,16 b$ \\
\hline SMC + micronutrientes (CMS + Micronutrient) & $1,37 \mathrm{a}$ & $0,17 \mathrm{a}$ & 3,36 & 1,56 & 0,76 & $0,15 b$ \\
\hline \multicolumn{7}{|l|}{ SMC + micronutrientes + nematicida } \\
\hline CMS + Micronutrient + Nematicide & $1,28 \mathrm{a}$ & $0,18 \mathrm{a}$ & 3,62 & 1,97 & 0,62 & $0,15 b$ \\
\hline Médias (Means) & 1,19 & 0,17 & 3,31 & 1,84 & 0,59 & 0,17 \\
\hline $\mathrm{CV}(\%)$ & 18,34 & 36,82 & 19,56 & 27,14 & 26,87 & 16,92 \\
\hline
\end{tabular}

Médias seguidas pela mesma letra, no sentido da coluna, não diferem entre si $(P>0,05)$ pelo teste de Scott-Knott.

Means followed by the same letter in the same column do not differ $(P>.05)$ by Scott-Knott test.

* Não-significativo pelo teste $F(P>0,05)$.

* Not significant according to $F$ test $(P>.05)$.

de tratamento do SMC, observou-se o efeito da subtração do nitrogênio na percentagem deste mineral na palma forrageira $(0,79 \%)$.

Considerando os teores de nitrogênio, estimaram-se os valores de proteína bruta. Assim, a média geral dos tratamentos para proteína bruta foi de 7,41\%, superior às encontradas por Santos (1992), que foi de $6,50 \%$. Isto, possivelmente, deveu-se à idade da planta, posto que, no trabalho supracitado, o teor de proteínas foi estimado em plantas com 20 meses de idade, enquanto, no presente trabalho, as avaliações foram realizadas em plantas com nove meses de idade. Este fato era esperado, uma vez que os teores de matéria seca são diretamente proporcionais e os de proteína bruta são inversamente proporcionais à idade da planta. Vale ressaltar também que os teores médios de proteína mais elevados nesse trabalho, em relação à literatura (Santana et al., 1972; Cunha, 1996; Santos et al., 1998; Farias et al., 2000; Wanderley, 2001), podem também estar associados à utilização de adubação neste experimento, além das diferentes condições em que foram realizados (casa de vegetação e campo).
A média geral de potássio dos tratamentos foi de $3,31 \%$, superior às encontradas por Santos (1992) e Nefzaoui e Bem Salen (2001), de 1,16\% e 1,09\%, respectivamente. O teor médio de potássio no solo correspondeu a 6,1\% da CTC, proporção considerada elevada. O teor de K na palma não variou significativamente entre os tratamentos, resultando em valores médios acima dos reportados na literatura.

A média geral para cálcio foi de 1,84\%, variando de $2,10 \%$ para o valor máximo e $1,56 \%$ para o valor mínimo. Resultados semelhantes foram encontrados por Mattos (2000) e Nobel et al. (1987), que encontraram 2,00\% e 1,72\%, respectivamente. Berry e Nobel (1985), avaliando o estresse mineral em duas espécies de cactácea (Opuntia ficus-indica e Ferocactus acanthodes), encontraram que nenhuma das duas espécies requeriam altos níveis de Ca na solução do solo e que as mesmas não foram influenciadas por uma variação de $\mathrm{pH}$ de 4,5 até 8,5. Esses autores afirmam ainda que os altos níveis de Ca encontrados na parte aérea da Opuntia ficus-indica refletem o acúmulo deste mineral na forma de oxalato. 
Os valores médios de Ca e P observados apresentaram relação média Ca:P de 10,8:1, valor considerado elevado se comparado com outras forrageiras que possuem relações Ca:P entre 2:1 e 4:1 (Tebaldi et al., 2000). Andrade et al. (2002), verificando o efeito da substituição da silagem de sorgo pela palma forrageira (Opuntia ficus-indica) constataram efeito quadrático na absorção de Ca, P e Na e aumento linear na absorção de K com o aumento do nível de palma na dieta. Os mesmos autores verificaram que a proporção Ca:P na dieta que propiciou a melhor absorção desses elementos por vacas em lactação foi de 1,9:1. O teor de Ca recomendado pelo NRC (2001), para vacas em lactação (peso vivo de 650 kg e produção diária de 25 kg leite) é de $0,74 \mathrm{dag} \mathrm{kg}^{-1}$, valor abaixo do observado para palma forrageira neste trabalho. Esse é um aspecto que deve ser levado em consideração quando do fornecimento de grandes quantidades de palma para ruminantes. A adubação fosfatada modificou os teores de Ca e de P de 0,14 e $2,10 \%$ para 0,23 e $1,96 \%$, respectivamente, diminuindo a relação Ca:P de 15:1 para 8,5:1.

Para o teor de magnésio, a média geral foi de $0,59 \%$, porém valor superior foi encontrado por Germano et al. (1991) (2,14\%). Nobel et al. (1987) encontraram para teor de magnésio $0,45 \%$, para a palma Opuntia engelmannii. Araújo Filho (2000), avaliando, em casa de vegetação, o efeito da adubação fosfatada e potássica sobre o desenvolvimento da palma forrageira cv. IPA 20 cultivada em solo proveniente de Arcoverde - PE, constatou que as doses de $\mathrm{P}$ testadas promoveram decréscimo nos teores de N, Ca e Mg, elevando os teores de K e S. Por outro lado, as doses de $\mathrm{K}$ aplicadas reduziram os teores de Ca e aumentaram os teores de S. Os teores de micronutrientes, por sua vez, não foram afetados pelas adubações fosfatada e potássica.

Para os teores de nitrogênio, fósforo e enxofre, a análise de variância indicou diferença significativa $(\mathrm{P}<0,05)$ entre os tratamentos pelo teste $\mathrm{F}$. Os tratamentos em que foi adicionado nitrogênio apresentaram maiores níveis deste mineral na planta como esperado, em relação aos demais tratamentos, exceto o tratamento-testemunha mais enxofre que também se apresentou superior aos demais, o que pode estar relacionado ao fato de que o enxofre participa da molécula de proteína. O teor médio encontrado para nitrogênio foi de 1,19\%, tendo como limites mínimo e máximo os valores de 1,52\% e $0,79 \%$, respectivamente. Nobel (1995) afirma que os cinco elementos do solo que parecem exercer maior efeito sobre o desenvolvimento da Opuntia são o N, $\mathrm{P}, \mathrm{K}, \mathrm{B}$ e Na. O mesmo autor afirma que, de maneira geral, adubações nitrogenadas aumentam a produtividade de Opuntia ficus-indica.

Para o teor de fósforo na planta, o tratamento testemunha que recebeu adubação química a base de fósforo apresentou um dos maiores teores desse elemento, sendo de $0,23 \%$. A aplicação de $P$, sem a aplicação de outros nutrientes, possivelmente elevou a concentração deste elemento $(\mathrm{P})$ na planta, pois o crescimento foi provavelmente limitado pelos outros nutrientes, não ocorrendo assim o efeito de diluição do fósforo. A média geral dos tratamentos foi de $0,17 \%$ de $\mathrm{P}$, semelhante à encontrada por Mattos (2000) e superior às registradas por Santos (1992) e Gathaara et al. (1989), de $0,094 \%$ e $0,050 \%$ de fósforo, respectivamente. No presente trabalho, de maneira geral, a adição de N, P e K aumentou a proporção destes minerais, em relação ao tratamentotestemunha. Baca Castillo (1988), induzindo deficiências de nutrientes na palma forrageira cultivada em solução nutritiva, concluiu que os nutrientes P, N, K, Ca, B, Mg, Fe e Mn foram, em ordem decrescente de importância, os que provocaram maior redução na velocidade de crescimento na palma, quando se encontravam em níveis baixos no solo.

Para porcentagem de enxofre, não foram encontradas na literatura informações acerca de sua proporção na planta. Os tratamentos experimentais influenciaram a porcentagem de enxofre na planta. Os tratamentos testemunha, SMC com subtração de $\mathrm{N}, \mathrm{K}, \mathrm{Ca}$ e $\mathrm{Mg}$, testemunha mais adição de $\mathrm{P}$ e nematicida diferiram estatisticamente dos demais tratamentos, apresentando maiores teores de enxofre, variando de $0,18 \%$ a $0,22 \%$. A média de enxofre dos tratamentos foi de $0,17 \%$.

A adição de micronutrientes e de nematicida não apresentou efeito significativo $(\mathrm{P}>0,05)$ para os teores de N, P, K e S na planta.

Na Tabela 2, encontram-se os dados relativos à concentração dos minerais no perfil da planta. Os teores de nitrogênio, fósforo e potássio foram superiores nos artículos secundários, o que pode estar associado à elevada mobilidade destes minerais (Malavolta et al., 1974) e à idade avançada da planta (Corsi \& Silva, 1994; Malavolta, 1997), como pode ser observado nos artículos mais velhos (os primeiros). Para cálcio e magnésio, os teores foram superiores 
Tabela 2 - Intervalo de confiança da média para os teores de nitrogênio $(N)$, fósforo $(P)$, potássio $(K)$, cálcio $(\mathrm{Ca})$, magnésio $(\mathrm{Mg})$ e enxofre (S) por ordem de artículo da palma forrageira cv. gigante aos nove meses de idade

Table 2 - Mean confidence interval for N, P, K, Ca, Mg and, $S$ concentrations according the cladode order in cactus forage $\mathrm{cv}$ "Gigante" at nine months of regrowth

Minerais (\%) Artículos primários Artículos secundários

\begin{tabular}{lcc} 
Minerals (\%) & Primary cladodes & Secundary cladodes \\
\hline $\mathrm{N}$ & $1,16 \pm \pm 0,17$ & $1,56 \pm \pm 0,14$ \\
$\mathrm{P}$ & $0,17 \pm \pm 0,03$ & $0,22 \pm \pm 0,04$ \\
$\mathrm{~K}$ & $3,22 \pm \pm 0,18$ & $3,85 \pm \pm 0,36$ \\
$\mathrm{Ca}$ & $2,02 \pm \pm 0,14$ & $0,95 \pm \pm 0,12$ \\
$\mathrm{Mg}$ & $0,63 \pm \pm 0,04$ & $0,43 \pm \pm 0,06$ \\
$\mathrm{~S}$ & $0,17 \pm \pm 0,01$ & $0,17 \pm \pm 0,01$ \\
\hline
\end{tabular}

$(\mathrm{P}<0,05)$.

nos artículos primários, o que pode estar associado à relativa imobilidade desses elementos na planta (Epstein, 1975). Para enxofre, apesar de ser considerado um mineral móvel (Malavolta et al., 1974), observaram-se níveis semelhantes nas ordens de artículos estudadas.

Considerando a composição mineral da palma, registrou-se elevada extração de minerais, o que sinaliza a importância de reposição desses nutrientes em áreas de cultivo da palma. Evidentemente, manejos que promovam maiores produtividades levam a necessidade de um aumento desde que na avaliação e escolha de tratamentos de adubação sejam consideradas informações de composição mineral da planta e de produção de matéria seca. Neste sentido, Teles et al. (2002) observaram que o grupo dos tratamentos SMC apresentou maior produção de matéria seca que o grupo das testemunhas, evidenciando o efeito da fertilidade do solo na produção de matéria seca da palma forrageira.

\section{Conclusões}

Os tratamentos experimentais não influenciaram os teores de matéria seca, potássio, cálcio e magnésio da palma forrageira.

Nitrogênio, fósforo e enxofre foram os únicos nutrientes que influenciaram as características estudadas.

Os teores de nitrogênio, fósforo e potássio foram superiores nos cladódios mais jovens da planta.

R. Bras. Zootec., v.33, n.6, p.1992-1998, 2004 (Supl. 2)

\section{Literatura Citada}

ANDRADE, D.K.B.; FERREIRA, M.A.; VÉRAS, A.S.C. et al. Digestibilidade e absorção aparentes em vacas aça holandesa alimentadas com palma forrageira (Opuntia ficusindica, Mill) em substituição à silagem de sorgo (Sorghum bicolor (L.) Moench). Revista Brasileira de Zootecnia, v.31, n.5, p.2088-2097, 2002.

ARAÚJO FILHO, J.T. Adubação mineral de palma forrageira. Recife: Universidade Federal Rural do Pernambuco, 2000. 90p. Dissertação (Mestrado) - Universidade Federal Rural do Pernambuco, 2000.

BACA CASTILLO, G.A. Deficiencias nutrimentales inducidas en nopal proveniente de cultivo in vitro. In: REUNIAO NACIONAL E INTERNATIONAL SOBRE CONOCIMENTO Y APROVECHAMENTO DEL NOPAL, 1 e 3, 1988, Saltilho. Memórias... Saltilho: Universidad Autonoma Agraria, 1988. p.155-163.

BERRY, W.L.; NOBEL, P.S. Influence of soil and mineral stresses on cacti. Journal of Plant Nutrition, v.8, n.8, p.679-696. 1985.

BEZERRA NETO, E.; ANDRADE, A.G.; BARBOSA, L.P. Análise química de tecidos e produtos vegetais. Universidade Federal Rural do Pernambuco, 1994. 99p.

CORSI, M.; SILVA, R.T.L. Fatores que afetam a composição mineral de plantas forrageiras. In: PEIXOTO, A.M. et al. Pastagens: Fundamentos da exploração racional. Piracicaba: Fundação de Estudos Agrários Luiz de Queiroz, 1994. p.65-83.

COSTA, B.M.C.; MENDONÇA, C.A.G.; CALAZANS, J.A.M. Forrageiras arbóreas e suculentas para formação de pastagens. Cruz das Almas: IPEAL, 1973. p.15-19. (Circular Técnico, 34).

CUNHA, M.G.G. Efeito da adição de fibra em dietas à base de palma forrageira (Opuntia ficus indica Mill) sobre os parâmetros da fermentação ruminal e da digestibilidade em ovinos. Recife: Universidade Federal Rural de Pernambuco, 1996. 70p. Dissertação (Mestrado em Zootecnia) - Universidade Federal Rural de Pernambuco, 1996.

EMPRESA BRASILEIRA DE PESQUISA AGROPECUÁRIA - EMBRAPA. Serviço Nacional de Levantamento e Conservação de Solos. Manual de métodos de análises de solo. Rio de Janeiro: 1979. Não paginado.

EPSTEIN, E. Nutrição mineral das plantas; princípios e perspectivas. Livros Técnicos e Científicos Editora S.A. e Editora da Universidade de São Paulo. 341p. 1974.

FARIAS, I.; LIRA, M.A.; SANTOS, D.C. et al. Efeito da freqüência e intensidade de corte em diferentes espaçamentos na cultura da palma forrageira (Opuntia ficus indica Mill), em consórcio com sorgo granífero (Sorghum bicolor (L.) Moench). Pesquisa Agropecuária Pernambucana, v.6, n.especial, p.169-183, 1989.

FARIAS, I.; LIRA, M.A.; SANTOS, D.C. et al. Manejo de colheita e espaçamento da palma-forrageira em consórcio com sorgo granífero, no Agreste Pernambuco. Pesquisa Agropecuária Brasileira, v.35, n.2, p.341-347, 2000.

GATHAARA, G.N.; FELKER, P.; LAND, M. Influence of nitrogen and phosphorus application on Opuntia engelmannii tissue $\mathrm{N}$ and $\mathrm{P}$ concentrations, biomass production and fruit yelds. Journal of Arid Environments, v.16, p.337-346, 1989. 
GERMANO, R.H.; BARBOSA, H.P.; COSTA, R.G. et al. Avaliação da composição química e mineral de seis cactáceas do semi - árido paraibano. In: REUNIÃO DA SOCIEDADE BRASILEIRA DE ZOOTECNIA, 28., 1991. João Pessoa. Anais... João Pessoa: Sociedade Brasileira de Zootecnia, 1991. p.3.

HOAGLAND, D.R.; ARNON, D.I. The water - culture method for growing plants without soil. California: Agri. Exp. Sta., 1950. 347p. (Circular)

LARCHER, W. Ecofisiologia vegetal. São Paulo: EPU, 1986. 319p.

MALAVOLTA, E. ABC da adubação. 4 ed. São Paulo: Ceres. 1979.

MALAvolta, E. Avaliação do estado nutricional das plantas: Princípios e aplicações. 2.ed. Piracicaba: POTAFOS, 1997. p.246-250.

MALAVOLTA, E.; HAAG, H.P.; MELLO, F.A.F. et al. Nutrição mineral e adubação de plantas cultivadas. São Paulo: Pioneira, 1974. 724p.

MATTOS, L.M.E. Associação da palma forrageira (Opuntia ficus indica Mill) com diferentes fontes de fibra na alimentação de vacas mestiças em lactação. Recife: Universidade Federal Rural do Pernambuco, 2000. 51p. Dissertação (Mestrado em Zootecnia) - Universidade Federal Rural de Pernambuco, 2000.

NOBEL, P.S.; RUSSEL, C.E.; FELKE, P. et al. Nutrient relations and productivity of prikey pear cacti. Agronomy Journal. v.79, n.3, p.550-555, 1987.

NOBEL, P.S. Environmental biology. In: BARBERA, G; INGLESE, P.; PIMIENTA-BARRIOS, E. (Eds.) Agroecology, cultivation and uses of cactus pear. Rome: FAO, 1995. p.36-48.

NEFZAOUI, A.; BEN SALEM, H. Opuntia: a strategic fodder and eficient tool to combat desertification in the wana region. Disponível em: www. Fao.org/2001.

NATIONAL RESEARCH COUNCIL - NRC. Nutrient requirements of the dairy cattle. 7.rev.ed. Washington, DC.: 2001. 381p.

SANTANA, O.P.; VIANA, S.P.; ESTIMA, A.L. et al. A palma versus silagem na alimentação de vacas leiteiras. Revista da Sociedade Brasileira de Zootecnia, v.1, n.1, p.31-40, 1972.

SANTOS, D.C. Estimativa de parâmetros em caracteres de clones da palma forrageira (Opuntia ficus indica Mill e Nopalea cochenillifera Salm-Dick). Recife: Universidade Federal Rural de Pernambuco, 1992. 119p. Dissertação (Mestrado) - Universidade Federal Rural de Pernambuco, 1992.
SANTOS, D.C.; FARIAS, I.; LIRA, M.A. et al. A palma forrageira (Opuntia ficus indica Mill e Napalea cochenillifera Salm Dyck) em Pernambuco: cultivo e utilização. Recife: IPA, 1997. p.1-16.

SANTOS, M.V.F.; LIRA, M.A.; BURITY, H.A. et al. Número, dimensões e composição química de artículos de palma forrageira (Opuntia ficus indica Mill) cv. gigante, de diferentes ordens. Pesquisa Agropecuária Pernambucana, v.7, n.especial, p.69-79. 1990.

SANTOS, M.V.F.; FARIAS, I.; LIRA, M.A. et al. Colheita da palma forrageira (Opuntia ficus indica Mill) cv. gigante sobre o desempenho de vacas em lactação. Revista Brasileira de Zootecnia, v.27, p.33-39, 1998.

SILVA, D.J.; QUEIROZ, A.C. Análise de alimentos - métodos químicos e biológicos. 3.ed. Viçosa, MG: Univesidade Federal de Viçosa, 2002. 235p.

SCOTT, A.J.; KNOTT, M. A cluster analysis method for grouping means in the analysis of variance. Biometrics, v.30, n.3, p.507-512, 1974.

TEBALDI, F.H.L.; SILVA, J.F.C.; VASQUEZ, H.M. et al. Composição mineral das pastagens das regiões Norte e Noroeste do Rio de Janeiro. 1. Cálcio, fósforo, magnésio, potássio, sódio e enxofre. Revista Brasileira de Zootecnia, v.29, n.2, p.603-615, 2000.

TELES, M.M.; SANTOS, M.V.F.; DUBEUX Jr., J.C.B. et al. Efeito da adubação e de nematicida no crescimento e na produção da palma forrageira (Opuntia ficus indica Mill) cv Gigante. Revista Brasileira de Zootecnia, v.31, n.1, p.52-60, 2002.

VIANA, O.J. Pastagens de cactáceas nas condições do Nordeste. Zootecnia, v.7, n.2, p.55-61, 1969.

WANDERLEY, W.L. Palma forrageira (Opuntia fícus indica Mill) em substituição à silagem de sorgo (Sorghum bicolor (L.) Moench) na ração de vacas holandesas em lactação. Recife: Universidade Federal Rural do Pernambuco, 2001. 41p. Dissertação (Mestrado em Zootecnia) - Universidade Federal Rural do Pernambuco, 2001. 